\title{
ВИЗУАЛИЗАЦИЯ КОНЦЕПТА «СИБИРСКИЙ ЭТНОС》 В ТВОРЧЕСТВЕ КРАСНОЯРСКОГО ХУДОЖНИКА КОНСТАНТИНА ВОЙНОВА
}

\author{
И. А. Пантелеева \\ Сибирский федеральный университет, г. Красноярск, Российская Федерация
}

Информация о статье

Дата поступления

6 апреля 2018 г.

Дата принятия к печати 21 мая 2018 г.

Дата онлайн-размещения 8 июня 2018 г.

\section{Ключевые слова}

Визуальный концепт; этнос; визуальное мышление; художественный образ; идеальное; репрезентация; Константин Войнов; живопись

\begin{abstract}
Аннотация
Статья посвящена анализу особенностей визуального концепта «сибирский этнос» в творчестве красноярского художника Константина Войнова. Исследование визуальных концептов особенно продуктивно в эпоху иконического поворота, поскольку позволяет раскрыть содержание культурных смыслов, не нашедших достаточного отражения в вербальных текстах, но успешно репрезентированных в визуальных форматах. Методологическими основаниями работы стали: синтетическая теория идеального Д. В. Пивоварова, концепция визуального мышления В. И. Жуковского, концепция «визуального поворота» в культуре, теория концепта Ю. С. Степанова, метод философского искусствоведческого анализа произведений художественной культуры. Содержание концепта «сибирский этнос» рассматривается в следующих аспектах: комплекс представлений о народах, искони населявших территорию Сибири, репрезентация культуры «пришлого» (некоренного) населения, национальность "сибиряк» как ценностное отношение причастности к великому региону, обладающему в современных представлениях особой гармонией, чистотой и первозданностью. Представлен анализ репрезентативных произведений цикла живописных работ К. С. Войнова «Этника Сибири». Художественный образ в работах цикла раскрывается посредством репрезентации всеобщего через единичное, представления образа человека, живущего в согласии с окружающим миром, Богом и самим собой. Через изображение этнических особенностей автор поднимается до общечеловеческого, вневременного содержания - рождения жизни, отношений матери и ее ребенка, осмысления хода человеческой жизни, диалектики жизни и смерти и т. д.
\end{abstract}

\section{VISUALIZATION OF THE CONCEPT «SIBERIAN ETHNOS》 IN THE WORKS BY THE KRASNOYARSK ARTIST KONSTANTIN VOYNOV}

Irina A. Panteleeva

Siberian Federal University, Krasnoyarsk, the Russian Federation

Article info

Received

April 6, 2018

Accepted

May 21, 2018

Available online

June 8, 2018

\section{Abstract}

The article is devoted to the research of specific features of the visual concept «Siberian ethnos» in the works by Krasnoyarsk painter Konstantin Voynov. Research of visual concepts is especially productive in the epoch of iconic turn, since it allows to reveal the content of cultural meanings which weren't sufficiently reflected in verbal texts, but were successfully represented in visual forms. Methodologic grounds for the work are synthetic theory of the ideal by Daniil V. Pivovarov, concept of visual thinking by Vladi- 


\section{Keywords}

Visual concept; Siberian ethnos; visual thinking; word-picture; ideal; representation; Konstantin Voynov; painting mir I. Zhukovsky, concept of visual turn, concept theory by Yuriy S. Stepanov, method of philosophical and art analysis of artistic culture works. Content of the concept "Siberian Ethnos» is seen in the following aspects: a complex of images about folks who originally inhabited Siberian territory, representations of non-indigenous peoples' culture, nationality "Siberian» in terms of values-based attitude of belonging to the great region, which possesses peculiar harmony, purity, primevalness. Analysis of resemblant works of art of Konstantin S. Voynov's paintings cycle "Siberian Ethnicity" is presented in the article. Word-picture in the cycle works is revealed by means of representation of the universal through the single, presentation of the image of the person who lives with integrity and in line with nature and God. By painting ethnic features, the author goes up to the universal human, supertemporal content - birth, relationship between mother and her child, understanding the course of human life, dialectics of life and death, etc.
Исследование концептов в современном гуманитарном знании является одним из продуктивных ходов по выявлению содержания той или иной культуры. Изучение визуальных концептов в эпоху иконического поворота дает возможность раскрытия таких культурных смыслов, которые не нашли (нашли недостаточно) ффиксации в вербальных текстах, но успешно репрезентированы в визуальном формате и могут быть корректно расшифрованы с помощью визуального мышления, т. е. такого вида мышления, которое посредством оперирования иконическими знаками позволяет увидеть результат рационального познания, вывести его из сфреры абстрактного бытия в пространство чувственно постигаемого.

Методологическими основаниями данной работы послужили:

1. Синтетическая теория идеального Д. В. Пивоварова, позволяющая рассматривать культуру как процесс и пространство идеалообразования, т. е. создания особых эталонных объектов (в материальной или нематериальной форме), практики или схемы действия по созиданию (освоению) данных объектов, а также как субъектное, интериоризированное качество объекта, возникающее в результате осуществления определенной схемы действия.

2. Концепция визуального мышления (как одного из аспектов синтетического мышления) В. И. Жуковского [1], предоставляющая возможность корректного оперирования специфическими знаками языка как репрезентантами осваиваемых явлений (визуальными знаками).

3. Предложенный В. И. Жуковским и Д. В. Пивоваровым метод философрско-искусствоведческого анализа произведений художественной культуры, основанный на последовательном применении общенауч- ных методов исследования (наблюдения, измерения, интерпретации, аналогии, формализации, индукции, дедукции, экстраполяции), позволяющий осуществить корректный перевод визуальных знаков на вербальный язык.

4. Теория концепта Ю. С. Степанова, дающая возможность рассматривать его как синтетическую вербально-образную репрезентацию культуры в сознании человека. В данной работе методология применена для понимания сути концепта «сибирский этнос» в произведениях художественной культуры.

5. Концепция «визуального (или «иконического» (Г. Бем), или «пикториального» (У. Митчел)) поворота» в культуре (В. Беньямин, Ж. Бодрийяр, Р. Барт, Ж. Деррида, М. Фуко и др.), позволяющая не только исследовать концепты как вербальные конструкты культуры, но и изучать их образный, визуальный контекст.

Термин «концепт», ранее разрабатываемый лингвистами, сегодня актуален и в других областях гуманитарного знания (когнитивной психологии, социальной и культурной антропологии, культурологии, истории и др.), что дало целый спектр его пониманий. Так, концепт является междисциплинарным образованием и используется целым рядом наук, что также свидетельствует о его сложности и многомерности. Согласно С. А. Аскольдову, концепт рассматривается «как многомерный мыслительный конструкт, отражающий процесс познания мира, результаты человеческой деятельности, его знания и опыт о мире, хранящий инфрормацию о нем» [2]. М. А. Холодная понимает концепт как «познавательную психическую структуру, особенности организации которой обеспечивают возможность отражения действительности в единстве разнокачественных аспектов» 
[3, с. 40-59]. Ю. С. Степанов разводит термины «понятие» и «концепт» и рассматривает последний как «основную ячейку культуры в ментальном мире человека», синтезирующую несколько смысловых слоев, по-разному реализующихся для разных людей одной культуры $[4$, с. 1924]. В. И. Карасик отмечает три важнейших компонента концепта - понятийный, образный и ценностный [5]. Об этом же пишет М. М. Ангелова: «Концепты не обязательно должны иметь вербализованную форму, хотя, как правило, они знаково оформлены (вербализованы)» [6]. Но при этом вербальный (понятийный) компонент концепта не является доминирующим, Он находится в равноправном диалоге с образным и ценностным компонентами. Кроме того, классифицируя концепты, исследователи выделяют научные, художественные и обыденные концепты в соответствии с тем или иным принципом освоения мира. Л. В. Миллер, анализируя понятие «художественная картина мира», пишет, что ее главным структурообразующим элементом является концепт, который «возбуждает определенную зону внутреннего художественного опыта субъекта, формируя при этом некое ассоциативно-смысловое ядро художественного впечатления» [7, с. 14]. Таким образом, концепт может быть рассмотрен как базисная единица коллективного опыта культуры, которая переживается индивидуальным сознанием в процессе интериоризации культурного опыта, включает понятийный, ценностный и образный компоненты, репрезентируется через знаки языка, причем не только вербального, но и в равной степени визуального. Поэтому концепты, оплотненные (явленные, воплощенные) в произведениях изобразительного, декоративно-прикладного искусства и архитектуры, - визуальные концепты, они могут быть прочитаны (раскрыты) посредством применения законов визуального мышления [8, с. 94-98]. В качестве метода прочтения концептов в произведениях предлагается метод философско-искусствоведческого анализа, позволяющий понимать визуальные тексты культуры и выявлять особенности репрезентации концептов в визуальных понятиях.

Одним из актуальных концептов, приобретающих большое значение в современных социально-политических и культурных условиях вслед за концептом “этнос», становится концепт «сибирский этнос». Даже самый поверхностный анализ понятийного слоя данного концепта дает несколько содержательных аспектов, синтезирующих содержание двух ключевых для культурологии концептов - «Сибирь» и «этнос». Концепт «этнос" раскрывает свое содержание в нескольких значениях (народ, племя, толпа, группа людей) и указывает на всякую совокупность одинаковых живых существ, имеющих некие общие свойства. Помимо единства территории и традиций, в формировании целостности этноса нашли свое отражение морфология культуры и логика ее развития [9, с. 263]. В качестве необходимых критериев, диффреренцирующих этнические группы, современные исследователи также предлагают: тип физического облика; единство происхождения; единство места проживания; единство языка; самоназвание (этноним) как важный элемент исторической памяти народа, позволяющий ориентироваться в диспозиции «мы - они», «свои - чужие» $[10 ; 11]$. Концепт «Сибирь» раскрывается как обширный по площади, но малозаселенный регион, климатически суровый и потому опасный для жизни человека. Однако при этом Сибирь понимается как богатейший своими природными ресурсами регион, обладающий уникальной флорой и фауной, полезными ископаемыми, огромными запасами пресной воды. Образный аспект концепта “Сибирь» в языке подразумевает следующий знако-символический ряд: суровый край, окраина мира, гиблое место, место ссылки, но и место, где «осталась природная чистота, духовная первозданность, где есть следы непосредственного творения Божиего. Пространства невообразимые, и здесь к этому проще прикоснуться, чем где быто ни было» [12]. Важным аспектом рассматриваемого концепта является описание его через народ, населяющий сибирские территории, т. е. через сибирский этнос. "Это территория многовекового взаимодействия славянских, тюрко-монгольских, угро-финских, палеоазиатских народов, пространство диалога христианства, ислама, буддизма, шаманизма, взаимодействия земледельческого и кочевого хозяйственных укладов, доиндустриального, индустриального и постиндустриального обществ» [13].

Чтобы понять, какова специфика художественного интереса к данной тематике, необходимо изучить следующие возможные аспекты (слои) содержания концепта «сибирский этнос»:

1. Во-первых, подразумевается весь комплекс понятий и представлений о корен- 
ных этносах, проживающих на обширной территории Сибирского региона, с их специфическими фенотипическими данными, традиционным, сложившимся в течение многих веков образом жизни, традиционными занятиями (промыслы, оленеводство, коневодство и т. д.), религиозным синкретизмом (тотемизм, шаманизм, православие, буддизм), особенной культурой. Этот аспект концепта включает в себя указание и на суровые природно-климатические условия (холодные зимы, полярную ночь, полярный день), и на особую стойкость характера людей, житейскую мудрость, смекалку, позволившую выжить в сложнейших природных условиях.

Интерес к культуре коренных народов, будь то малочисленные этносы Севера, Сибири и Дальнего Востока, индейцы Америки, саамское население Скандинавии, аборигенное население Индии, Юго-Восточной Азии или Австралии, сегодня в мире чрезвычайно велик. Связано это не только с активной деятельностью самих коренных народов по популяризации собственной этнической культуры и отстаиванию ими нормативно-правовых, фринансовых, социальных и иных мер по поддержке издревле сложившегося образа жизни, традиционных промыслов, пищевых обычаев и декоративно-прикладного творчества, направленных на сохранение самого этноса в условиях глобальных трансформаций. В настоящее время так называемые развитые общества, потерявшие собственные корни, неоднократно сменившие места обитания, забывшие традиционные занятия, образ жизни, обращаются к культуре этих народов в надежде обретения смысла бытия, прикосновения к всеобщей основе мира, находят в этой, казалось бы, «первобытной» культуре то, что было давно утрачено культурой «цивилизованной», массовой.

В этом же слое репрезентируются все трудности и проблемы жизнедеятельности коренных сибирских этносов в современном глобализирующемся мире, в том числе «наступление» цивилизации, разработка месторождений полезных ископаемых на территориях традиционного природопользования коренных народов, ассимиляция малочисленных этносов титульной нацией и т. д.

2. Вторым аспектом понятийного наполнения концепта является репрезентация культуры «пришлого» населения, причем если массированное освоение Сибири можно наблюдать начиная со второй половины
XVI в., то первые контакты жителей европейской части России (населения Новгородской республики) с коренными этносами Сибири известны еще с XI в. Это и добровольное переселение жителей европейских территорий России на сибирские территории в поисках лучшей жизни, и политическая ссылка (польские повстанцы), и депортация народов в XX в. (немцев, калмыков, эстонцев, латышей, литовцев и т. д.), и волны трудовой миграции начала XXI в.

3. Третьим содержательным аспектом, репрезентирующим в первую очередь ценностный аспект концепта «сибирский этнос», стала ситуация, возникшая в ходе Всероссийской переписи населения 2010 г., когда жители ряда сибирских регионов в графре «Национальность» просили переписчиков указать «сибиряк». Этот фракт свидетельствует не столько о констатации региона проживания человека, сколько о ценностном восприятии им того фракта, что он причастен к той могучей, великой территории, которая по сию пору сохранила свою первозданность и своеобразную чистоту в представлениях людей. Человек испытывает гордость от того, что и он сам смог встроиться в эту суровую природную красоту, этот естественный уклад, жить в гармонии с окружающим миром. И неважно, на этой территории его корни или его предки пришли сюда из других мест, он ощущает свое родство с этим местом и гордится тем, что он сибиряк.

В данной работе предлагается рассмотреть содержание концепта «сибирский этнос» через анализ живописных работ красноярского художника Константина Войнова.

Константин Семенович Войнов, ныне здравствующий художник, график и живописец, заслуженный художник России, член-корреспондент Российской академии художеств, проживает и ведет активную творческую деятельность в Красноярске.

Произведения, создаваемые художником в процессе творческой деятельности, объединяются им самим в циклы работ: «Правители», «Герои СССР», «Этника Сибири» и т. д. Художник проявляет себя в разных живописных и графических жанрах: в пейзаже, где через разные состояния сибирской природы репрезентируется мощь и красота сибирского региона; в жанровой картине, где, казалось бы, случайно увиденная художником сцена отсылает зрителя к мудрости христианской или индийской древней философии; в натюрморте, где все богатство и многообразие мира репре- 
зентировано через тщательно отобранные фрагменты бытия. Однако основным, наиболее интересным для художника жанром является портрет. Сам мастер о портрете: «Человеческая личность, наверное, самая необъятная и непостижимая сорера для художника и поэтому, возможно, самая интересная и трудная. А главная привлекательность для художника в жанре портрета заложена в неповторимости и уникальности каждого человека. Поэтому перед портретистом стоит огромная ответственность и труднейшая задача, оставшись самим собой, создать на холсте линейно-красочный аккорд, адекватный характеру и сущности портретируемого» ${ }^{1}$. По сути, центром всего творчества художника является человеческая личность, грани ее характера, общество, ее окружающее, мир, в котором она себя реализует. Хотя исследователи и определяют манеру письма Войнова как реалистичную, при этом можно говорить и о романтизации портретируемых персонажей, и об их идеализации. Художник в обыденном, ежедневном, традиционном видит вневременное, идеальное, образцовое. Это в полной мере характерно и для живописного цикла «Этника Сибири». Исследуя живописные работы, нельзя не вспомнить о тех художественных традициях, тех мастерах, которые где-то напрямую, а где-то опосредованно вдохновили мастера на обращение к теме коренных сибирских этносов. Ту же чистоту чувств и отношений, первозданность и естественность мира искал в свое время Поль Гоген на Таити, суровый северный край с его строгими правилами жизни писал Рокуэлл Кент на Аляске, Огненной Земле и в Гренландии. То же богатство сибирской и северной природы, бескрайние степи, могучая тайга вдохновляли художников красноярской школы Д. И. Каратанова, А. П. Лекаренко, Б. Я. Ряузова, Т. В. Ряннеля и др. Своеобразная экзотика жизни, быта и культуры коренных сибирских народов очаровала художников Д. И. Каратанова, А. П. Лекаренко, А. Г. Варгина и сподвигла их во время Всесоюзной переписи населения 1926-1928 гг. вместе с бригадой переписчиков в течение почти двух лет путешествовать по территории Эвенкии и севера Красноярского края, репрезентируя быт, традиции и культуру северных народов в своих зарисовках (рис. 1, 2).

1 Константин Войнов: художник-живописец. URL: http: //www.voinov-k.ru.

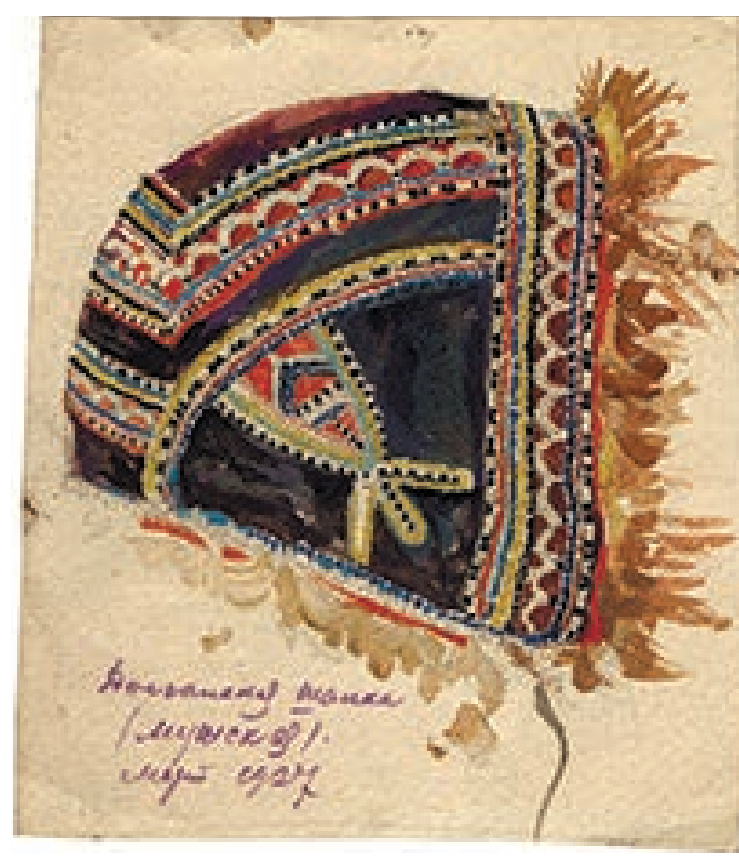

Рис. 1. А. П. Лекаренко. Долганская шапка. 1927. Картон, акварель. Красноярский краевой краеведческий музей

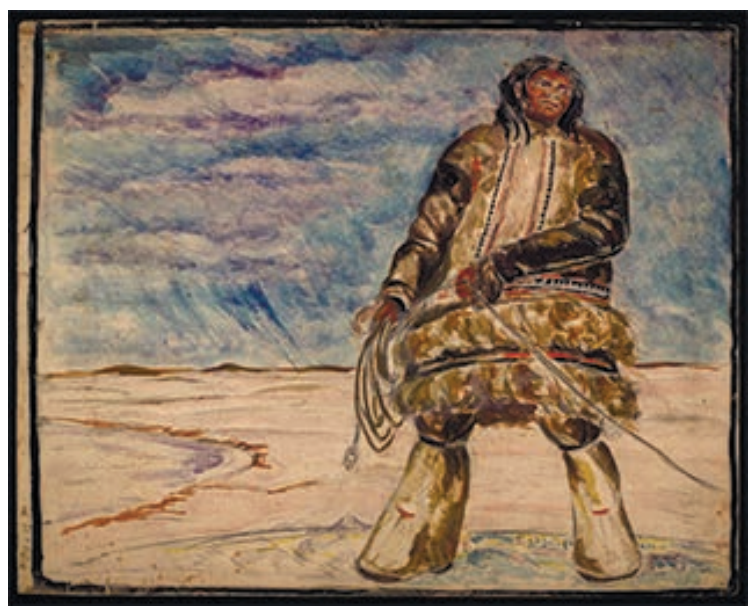

Рис. 2. А. П. Лекаренко.

Нганасан ловит оленей.

1926-1928. 34.3 × 42.5. Картон, акварель. Красноярский краевой краеведческий музей

Нужно сразу оговориться, что в данном случае мы имеем дело не с этнографическими зарисовками, как, например, в рисунках Д. И. Каратанова, А. П. Лекаренко, А. Г. Варгина 1926-1928 гг. Задача, поставленная художником Войновым в цикле «Этника Сибири», иная. Однако при работе над каждым произведением мастер самым тщательным образом изучал и френотипические особенности этноса, и его материальную культуру, и традиционный образ жизни.

Цикл «Этника Сибири» включает более 20 живописных работ, созданных в период 
2008-2016 гг., и может быть рассмотрен через такие репрезентативные полотна, как «Рождение», «Заполярная Мадонна», «Степная Мадонна», «Это жизнь», «Ловец солнца». Следует отметить, что работам этой серии свойственна композиция, которая может быть обозначена как «портрет в контексте», характеризующаяся присутствием одной-двух крупных человеческих фригур, представленных крупным планом в контексте их повседневного существования, их каждодневных занятий. При этом еще раз подчеркнем, что мастер дает собирательный, а не конкретный портретный образ, т. е. представляет своеобразный портрет «сибирского этноса».

Работа «Рождение» (рис. 3) представляет зрителю лежащего в традиционной нганасанской колыбели спящего младенца, одетого в традиционный нганасанский детский комбинезон минар. Колыбель изображена стоящей на как бы спускающейся с неба (из верхнего левого края холста) драпировке, сшитой из оленьих шкур и имеющей на оборотной стороне нарисованные знаки на фоне неба, окрашенного отблесками северного сияния. Олени, согласно мифам многих северных народов, были подарены людям богами и спущены на землю с небес. Олень сопровождает нганасанина не только в течение всей его жизни, но даже и после смерти. Это и еда, и одежда, и теплый дом, и средство передвижения, и ритуальная жертва в погребальном обряде. Весь мир нганасанина проходит рядом с этим животным. Композиция работы дает возможность корректного прочтения идеи произведения: рождение ребенка, дарованное небесами,представляется как рождение целого мира.

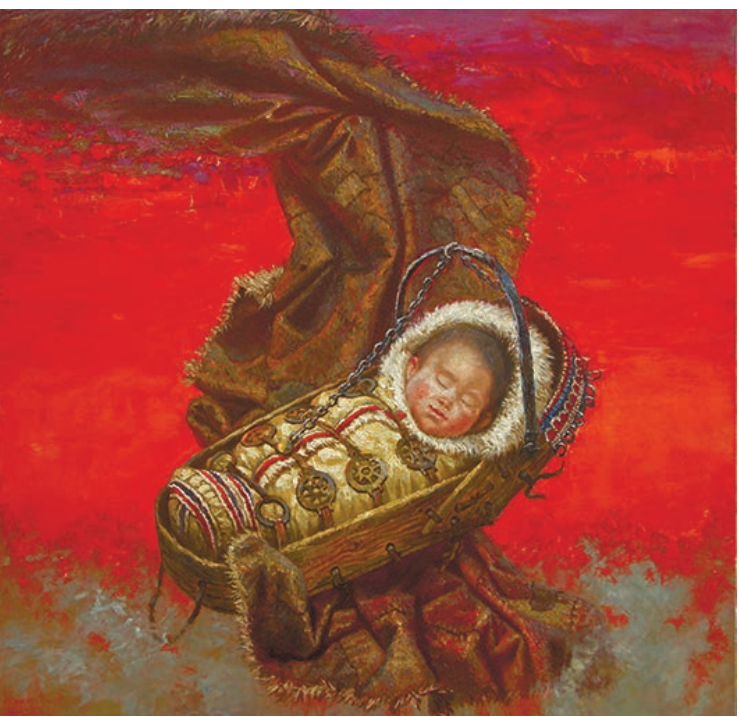

Рис. 3. К. С. Войнов. Рождение. 2010. $100 \times 100$. Холст, масло
Внутри цикла можно выделить группу работ, представляющих собой аллюзию на изображения Девы Марии с младенцем Христом. Это «Степная Мадонна», «Улыбка полярной звезды», «Заполярная Мадонна» (рис. 4) три работы, сходные по композиции. Основное пространство холста занято фригурой женщины - представительницы коренного сибирского этноса в национальном костюме (хакаска, нганасанка, долганка), держащей на руках (кормящей грудью) младенца. Остальное пространство холста всего лишь несколькими точными намеками обозначает этническую принадлежность персонажей - степи Хакасии с курганными камнями и пасущимися баранами, пространство нганасанского чума и нганасанская собака (порода собак, выращиваемая некоторыми северными народами, в том числе нганасанами). Таким образом, конкретно-личностное, единичное - изображение представительницы сибирского этноса, держащей на руках (кормящей грудью) младенца, - поднимается до уровня всеобщего, общечеловеческого, вызывает устойчивые аналогии с христианской историей, историей человечества. Композиционная формула этих работ, представленная треугольником с вершиной, устремленной вверх, демонстрирует имманационную тенденцию в системе идеалов художественной культуры, тенденцию «развоплощения», восхождения энергии конечного начала к бесконечности через дематериализацию явленной формы [14, с. 68].

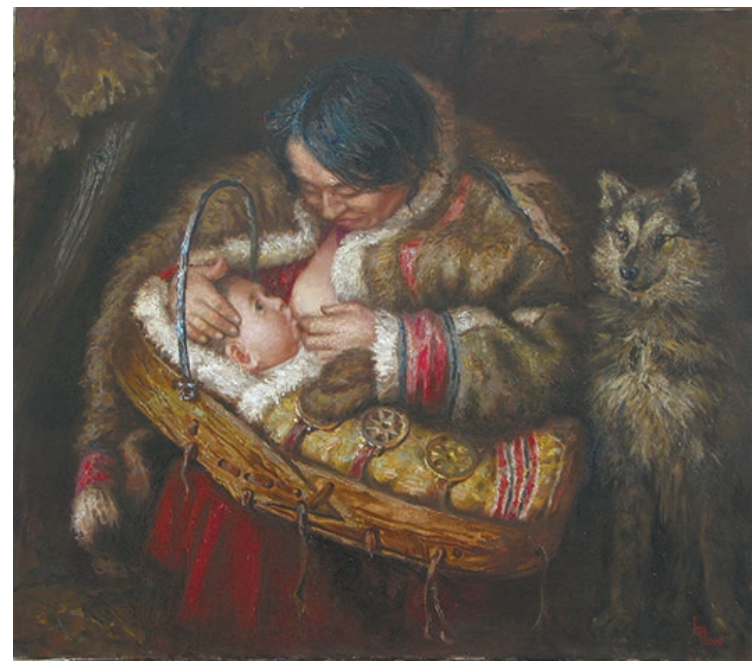

Рис. 4. К. С. Войнов. Заполярная мадонна. 2008. $70 \times 80$. Холст, масло

Обратимся к группе работ, репрезентирующих, с одной стороны, традиционные промыслы коренных сибирских этносов в актуально-этническом аспекте, а с другой стороны, представляющих эти занятия как 
естественные и жизненно необходимые для человечества в целом. Работа «Это жизнь» (рис. 5) являет собой изображение двух персонажей, идущих по берегу водоема на фоне очень низкой линии горизонта старика и мальчика. Персонажи одеты в традиционные долганские мужские костюмы соответственно возрасту каждого. Оба персонажа несут в руках рыбу: старик большую, мальчик - две небольшие по размеру рыбки. На первый взгляд, простая жанровая сцена, которая может быть определена как «рыбаки, возвращающиеся с уловом», трансорормируется в философствования относительно смены поколений, отношений между разными поколениями, хода жизни на земле и размышлений на тему жизненных ценностей.

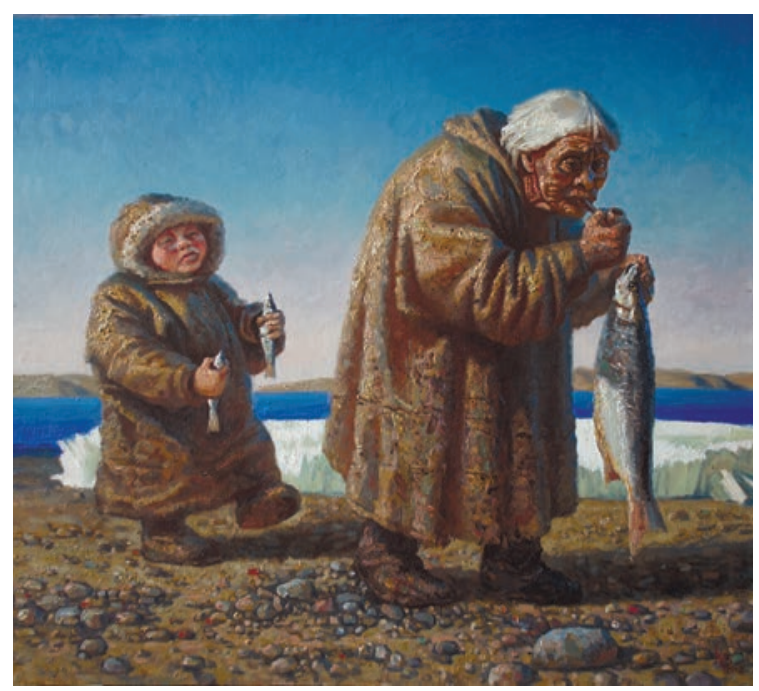

Рис. 5. К. С. Войнов. Это жизнь. 2012. $70 \times 80$. Холст, масло

Работа «Ловец солнца» (рис. 6) репрезентирует еще одно традиционное занятие коренных народов Сибири. В центре работы на фоне полярного неба и отблесков северного сияния представлен сибирский охотник в момент забрасывания тынзяна (аркана для ловли оленей). Однако его поза, взгляд, обращенный вверх, прищуренные глаза говорят о том, что тынзян забрасывается не на оленя - уставший от долгой полярной ночи человек ловит солнце. Символика солнца в мифологиях сибирских народов, живущих в ситуации смены полярного дня и полярной ночи, чрезвычайно значима. Поймать солнце - это значит оживить землю, дать возможность распуститься траве и цветам, спасти от голода и холода животных и людей.

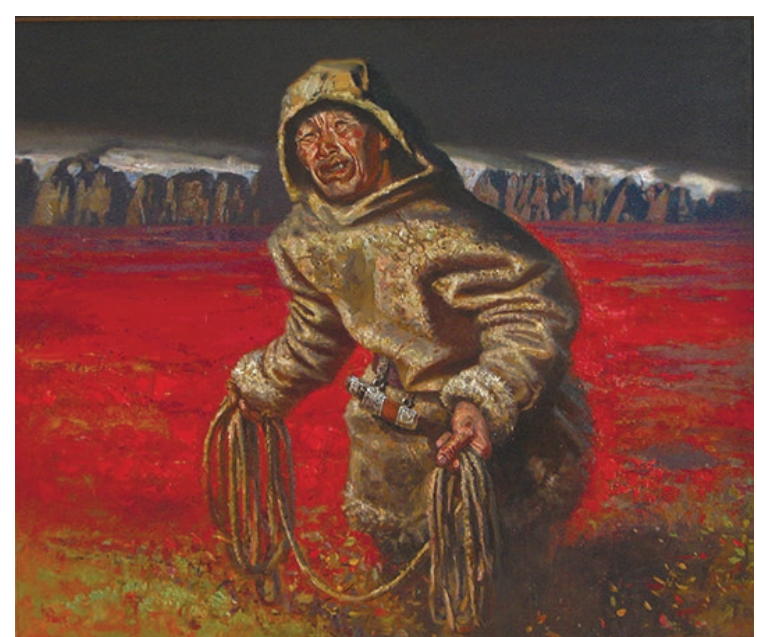

Рис. 6. К. С. Войнов. Ловец солнца. 2012. $100 \times 120$. Холст, масло

В процессе исследования живописного цикла «Этника Сибири» Константина Войнова художественный образ раскрывается посредством репрезентации всеобщего через единичное, представления образа человека, живущего в согласии с окружающим миром, Богом и самим собой. Концепт «сибирский этнос», с одной стороны, представлен в актуально-историческом, этническом аспекте через романтизированную репрезентацию традиционного облика, занятий, мест обитания коренных сибирских народов. С другой стороны, через изображение этнических подробностей автор поднимается до общечеловеческого, вневременного содержания рождение жизни, отношений матери и ее ребенка, осмысление хода человеческой жизни, диалектики жизни и смерти и т. д. Высказывание самого художника подтверждает результаты проведенного анализа: "Счастлив тем, что живу на красивейшей земле, протянувшейся вдоль енисейского меридиана, где волны могучего Енисея время от времени выносят на берег окаменелости доисторических существ и следы древних культур, где в хвойной тишине тайги и порывах степных ветров можно услышать легенды и предания древних племен, некогда населявших эти просторы и умеющих ладить с природой. Если просто взять, например, традиционную одежду долган или нганасан, то при внимательном, вдумчивом рассматривании и изучении можно насладиться удивительно живописной картиной, рассказывающей о чувствах, мечтах, представлениях о мире, о жизни и смерти. Для меня как для художника прикосновение к теме сибирской 
этники дало возможность создавать на холсте, может быть, идеализированный, но наполненный чистотой простых человеческих чувств и отношений мир, мир пер- возданной гармонии и природного целомудрия, мир, который мы, к сожалению, безвозвратно утрачиваем.... ${ }^{2}$

${ }^{2}$ Константин Войнов: художник-живописец.

\section{СПИСОК ИСПОЛЬЗОВАННОЙ ЛИТЕРАТУРЫ}

1. Жуковский В. И. Природа визуального мышления / В. И. Жуковский, Д. В. Пивоваров // Журнал Сибирского федерального университета. Гуманитарные науки. - 2008. - Т. 1, № 1. - С. 146-158.

2. Аскольдов С. А. Концепт и слово / С. А. Аскольдов // Русская словесность. От теории словесности к структуре текста. Антология / под ред. В. П. Нерознака. - М. : Academia, 1997. - С. 267-279.

3. КрасавскийН. А. Эмоциональные концепты в немецкой и русской лингвокультурах / Н. А. Красавский. Волгоград : Перемена, 2001. - 495 с.

4. Степанов Ю. С. Концепты. Тонкая пленка цивилизации / Ю. С. Степанов - М. : Языки славян. культур, 2007. - $248 \mathrm{c}$.

5. Карасик В. И. Семиотические типы концептов / В. И. Карасик // Вопросы когнитивной лингвистики. 2012. - № 4. - С. 5-11.

6. Ангелова М. М. «Концепт» в современной лингвокультурологии / М. М. Ангелова // Актуальные проблемы английской лингвистики и лингводидактики : сб. науч. тр. - М., 2004. - Вып. 3. - С. 3-10.

7. Миллер Л. В. Лингвокогнитивные механизмы формирования художественной картины мира : дис. ... д-ра филол. наук : 10.02.01 / Л. В. Миллер. - СПб., 2001. - 303 с.

8. Жуковский В. И. Теория изобразительного искусства / В. И. Жуковский - СПб. : Алетейя, 2011. - 496 с.

9. Григорьева И. В. Концепты «менталитет» и «этнос» в контексте изучения межэтнического диалога / И. В. Григорьева / / Ярославский педагогический вестник. - 2011. - Т. 1, № 4. - С. 259-265.

10. Арутюнов С. А. Народы и культуры: развитие и взаимодействие / С. А. Арутюнов. - М. : Наука, 1989. -247 c.

11. Бромлей Ю. В. Очерки теории этноса / Ю. В. Бромлей. - М. : Наука, 1983. - 412 с.

12. Хадаев А. Лицо сибирской национальности / А. Хадаев / / Российская газета. - 2011. - 5 апр.

13. Ерохина Е. А. Сибирский вектор внутренней геополитики России / Е. А. Ерохина ; под ред. Ю. В. Попкова. - Новосибирск : Изд-во НГУ, 2012. - 418 с.

14. Жуковский В. И. Идеалофундированная система культуры: принцип строения, диалектического самодвижения и саморазвития / В. И. Жуковский, М. В. Тарасова / / Философрия и культура. - 2011. № 6. - C. 65-72.

\section{REFERENCES}

1. Zhukovskii V. I., Pivovarov D. V. The Nature of Visual Thinking. Zhurnal Sibirskogo federal'nogo universiteta. Gumanitarnye nauki = Journal of Siberian Federal University. Humanities Sciences, 2008, vol. 1, no. 1, pp. 146158. (In Russian).

2. Askoldov S. A. The Concept and the Word. In Neroznak V. P. (ed.). Russkaya slovesnost'. Ot teorii slovesnosti k strukture teksta. Antologiya [Russian Philology. From the Theory of Philology to the Text Structure. Anthology]. Moscow, Academia Publ., 1997, pp. 267-279. (In Russian).

3. Krasavskii N. A. Emotsional'nye kontsepty v nemetskoi i russkoi lingvokul' turakh [Emotional Concepts in German and Russian Linguocultures]. Volgograd, Peremena Publ., 2001. 495 p.

4. Stepanov Yu. S. Kontsepty. Tonkaya plenka tsivilizatsii [Concepts. A Thin Film of Civilization]. Moscow, Yazyki slavyanskikh kul'tur Publ., 2007. 248 p.

5. Karasik V. I. Semiotic Types of Concepts. Voprosy kognitivnoi lingvistiki =Issues of Cognitive Linguistics, 2012, no. 4, pp. 5-11. (In Russian).

6. Angelova M. M. "The Concept» in the Contemporary Linguocultural Studies. Aktual'nye problemy angliiskoi lingvistiki I lingvodidaktiki [Topical Issues of English Linguistics and Language Education]. Moscow, 2004, iss. 3, pp. 3-10. (In Russian).

7. Miller L. V. Lingvokognitivnye mekhanizmy formirovaniya khudozhestvennoi kartiny mira. Dokt. Diss. [Linguo-cognitive mechanisms of the Artistic World-Picture. Doct. Diss.]. Saint Petersburg, 2001. 303 p.

8. Zhukovskii V. I. Teoriya izobrazitel' nogo iskusstva [Visual Art Theory]. Saint Petersburg, Aleteiya Publ., 2011. $496 \mathrm{p}$.

9. Grigoreva I. V. Concepts "Mentality» and «Ethnos» within the framework of the Inter-Ethnic Dialogue Studies. Yaroslavskii pedagogicheskii vestnik = Yaroslavl Pedagogical Bulletin, 2011, vol. 1, no. 4, pp. 259-265. (In Russian).

10. Arutyunov S. A. Narody i kul'tury: razvitie i vzaimodeistvie [Peoples and Cultures: Development and Interaction]. Moscow, Nauka Publ., 1989. 247 p.

11. Bromlei Yu. V. Ocherki teorii etnosa [Essays on the Ethnos Theory]. Moscow, Nauka Publ., 1983. $412 \mathrm{p}$

12. Khadaev A. A Person of Siberian Nationality. Rossiiskaya gazeta, 2011, April 5. (In Russian).

13. Erokhina E. A.; Popkov Yu. V. (ed.). Sibirskii vektor vnutrennei geopolitiki Rossii [Siberian Direction of Russian Internal Geopolicy]. Novosibirsk State University Publ., 2012. 418 p

14. Zhukovskii V. I., Tarasova M. V. The System of Culture Based on Ideals: Principle of Formation, Dialectical Self-Motion and Self-Development. Filosofiya i kul'tura = Philosophy and Culture, 2011, no. 6, pp. 65-72. (In Russian). 


\section{Информация об авторе}

Пантелеева Ирина Анатольевна - кандидат философских наук, доцент, кафедра рекламы и социально-культурной деятельности, Сибирский федеральный университет, 660041, г. Красноярск, пр. Свободный, 79, e-mail: panteleevaia@gmail.com.

\section{Для цитирования}

Пантелеева И. А. Визуализация концепта «сибирский этнос» в творчестве красноярского художника Константина Войнова / И. А. Пантелеева // Известия Байкальского государственного университета. - 2018. - T. 28, № 2. - C. 325-333. - DOI: $10.17150 / 2500-2759.2018 .28(2) .325-333$.

\section{Author}

Irina A. Panteleeva - Ph.D. in Philosophy, Associate Professor, Department of Advertising, Social and Cultural Studies, Siberian Federal University, 79 Svobodny Boulevard, 660041, Krasnoyarsk, the Russian Federation, e-mail: panteleevaia@gmail.com.

\section{For citation}

Panteleeva I. A. Visualization of the Concept "Siberian Ethnos» in the Works by the Krasnoyarsk Artist Konstantin Voynov. Izvestiya Baykal'skogo gosudarstvennogo universiteta $=$ Bulletin of Baikal State University, 2018, vol. 28, no. 2, pp. 325-333. DOl: 10.17150/2500-2759.2018.28(2).325-333. (In Russian). 